\title{
Short communication: Heritability of twinning rate in Holstein cattle
}

\author{
Beth M. Lett* and Brian W. Kirkpatrick ${ }^{*} \dagger^{1}$ \\ ${ }^{*}$ Department of Animal Sciences, and \\ †Department of Dairy Science, University of Wisconsin, Madison 53706
}

\section{ABSTRACT}

Multiple births or twinning in cattle is a naturally occurring reproductive phenomenon. For dairy cattle, twinning is considered a detrimental trait as it can be harmful to cow and calf as well as costly to the producer. The objective of this study was to examine recent US calving records for the Holstein breed to determine a current estimate of heritability for twinning rate along with effects of season and parity. Two models were used in this study: a linear sire model and a binary threshold-logit sire model. Both were mixed models considering fixed effects and random effects. Analyses were conducted using a restricted maximum likelihood method. Heritability estimates were $0.0192 \pm$ 0.0009 and $0.1420 \pm 0.0069$ for the linear and threshold models, respectively. Repeatabilities from the linear and threshold-logit models were $0.0443 \pm 0.0012$ and $0.2310 \pm 0.0072$, respectively. The nonzero estimates of heritability indicate the potential to select against this trait for genetic improvement of Holstein cattle.

Key words: twinning, heritability, dairy cattle

\section{Short Communication}

Twinning in cattle, especially dairy cattle, is viewed as a negative trait. This is due to the negative ratio of risk to reward in having twin births. There is still a debate about whether there is a benefit of increased milk production from dams that deliver multiple calves in a single calving (Kay, 1978; Kinsel et al., 1998; HosseinZadeh, 2010; Sawa et al., 2015) or whether there is a negative effect on milk production (Chapin and Van Vleck, 1980; Nielen et al., 1989; Fricke, 2001). However, even with increased milk production as a possible positive effect, it is associated with multiple negative effects such as abortion, dystocia, stillbirth, retained placenta, metabolic disorders, displaced abomasum, and ketosis (Fricke, 2001; Komisarek and Dorynek, 2002). Addi-

\footnotetext{
Received August 8, 2017.

Accepted December 11, 2017.

${ }^{1}$ Corresponding author: bwkirkpa@wisc.edu
}

tionally, there is the effect on future calving for the dam as twinning increases the calving interval and the time period between calving and conception and reduces mean lifetime production (Andreu-Vázquez et al., 2012). Twinning is neutral with regard to the proportion of fertile replacement female calves to infertile freemartin females from mixed-sex twin births (Komisarek and Dorynek, 2002). The neutrality is from the offset of fertile females from same-sex twin births, though the absolute number would be lessened owing to the lower perinatal survival rate of twins. Even though there is a chance to reduce some of these negatives with adjustments to management (e.g., changes to diet for twin-bearing cows, additional labor), these adjustments would result in increased costs. A range of approximately $\$ 50$ to $\$ 250$ loss per twin birth puts a large economic expense on twinning with very minimal, if any, benefits for twins in the dairy industry (Beerepoot et al., 1992; Fricke, 2001). Frequency of twinning in US Holstein cattle has been approximately 5\% (Cady and Van Vleck, 1978; Johanson et al., 2001), meaning an annual loss to the industry of $\$ 22.5$ to $\$ 112.5$ million assuming a national herd of 9 million cows.

Known contributing factors for twinning need to be accounted for when analyzing heritability. One such factor, as reviewed in Rutledge (1975), is the seasonal effect. This has been expressed as either the month or season of calving or conception, with conception months of September through October and March through April having the highest incidences. Another factor is parity of the dam. As the parity increases so does the chance of twinning, with the largest increase happening between the first and second parities (Rutledge, 1975; Johanson et al., 2001). These effects are presumably effects on ovulation rate, as incidence of monozygotic twinning is low and ovulation rate and twinning rate have a high genetic correlation (Van Vleck et al., 1991; Young and Kirkpatrick, 2016). Additionally, sires can have an influence on twinning rates in their daughters (Rutledge, 1975), suggesting a genetic component to variation. Johanson et al. (2001) grouped Holstein sires based on birth year and demonstrated that the sire group from the most current time points had more 
daughters with higher incidences of twinning. As with heritability, repeatability of twinning tends to be low (Syrstad, 1974; Rutledge, 1975). The objective of the current study was to estimate heritability and repeatability of twinning rate in US Holstein cattle using current calving record information for this population.

Calving records from the years 2010 to 2016 were obtained from AgSource Cooperative Services (Verona, WI). Initially, we obtained more than 2.9 million records from all breeds. Available information included cow, sire and dam identification (ID), herd, birthdate, calving date, parity, and multiple birth code. After editing, as described below, only the Holstein breed had sufficient records for estimation of heritability using a sire model. All other breeds had fewer than 20 sires represented in edited data versus more than 2,000 for the Holstein breed (Table 1). Consequently, efforts focused on data from Holsteins and records were removed if they were not Holstein for the cow, sire, and dam. Additionally, records were excluded if the cow, sire, or dam were missing part or all of their ID code or had codes indicating unknown ID. Records were also excluded if a cow had discrepant sire, dam, and birthdate information between records. Duplicate calving entries were eliminated such that there was 1 record per calving. Two sires and corresponding records were removed due to being listed both as a sire and as a cow. Suspected embryo transfer calvings were likewise excluded (indicated by multiple calvings within the same year for a cow). To increase the reliability of the genetic evaluation, only sires with $\geq 100$ daughter records were included in the final data set $(\mathrm{n}=2,223$; Figure 1$)$. Likewise, only herds with $\geq 100$ records were included (n = 1,748; Figure 1). After editing, 1,440,540 records with 658,436 cows remained for use in the analysis.

Preliminary fixed effects analysis was done using SAS 9.4 (SAS Institute Inc., Cary, NC). Variance components for heritability and repeatability calculations were estimated using ASreml 4.1 (VSN International, Hemel Hempstead, UK). Two models were used in alternative analyses: a linear sire model $(\mathbf{L M})$ and a binary threshold-logit sire model (TLM). The general form of the model in matrix notation was

$$
\mathbf{y}=\mathbf{X b}+\mathbf{Z s}+\mathbf{E p}+\mathbf{e}
$$

where $\mathbf{y}$ is a vector of calving phenotypes (singles or twins) for the LM and a vector of unobserved liabilities for twinning for the TLM; $\mathbf{X}$ is an incidence matrix relating phenotypes to fixed effects of herd, year, season, and parity; $\mathbf{b}$ is a vector of fixed effects; $\mathbf{Z}$ is a matrix relating phenotypes to sire genetic effects; $\mathbf{s}$ is a vector of sire additive genetic effects; $\mathbf{E}$ is a matrix relating phenotypes to permanent environmental effects; $\mathbf{p}$ is a vector of animal environments; and $\mathbf{e}$ is a vector of random residuals. The sire, permanent environment, and residual effects were random effects and herd, year, season, and parity were fixed effects. It was assumed for the LM that the random effects followed normal distributions of $s \sim N\left(0, \mathbf{A} \sigma_{s}^{2}\right), p \sim N\left(0, \mathbf{I} \sigma_{p}^{2}\right)$, and $e \sim N\left(0, \mathbf{I} \sigma_{e}^{2}\right)$, where $\sigma_{s}^{2}, \sigma_{p}^{2}$, and $\sigma_{e}^{2}$ represent additive genetic, permanent environment, and residual variances, respectively; A represents the numerator relationship matrix for sires; and $\mathbf{I}$ is the identity matrix. For the TML, random effects were assumed to have followed normal distributions of $s \sim N\left(0, \mathbf{A} \sigma_{s_{T}}^{2}\right), \quad p \sim N\left(0, \mathbf{I} \sigma_{p_{T}}^{2}\right), \quad$ and $e \sim N\left(0, \mathbf{I} \frac{\pi^{2}}{3}\right)$, where $\sigma_{s_{T}}^{2}, \sigma_{p_{T}}^{2}$, and $\frac{\pi^{2}}{3}$ represent additive genetic, permanent environment, and residual variances, respectively.

Parity for this data was categorized into 4 groups: parity $1(\mathrm{n}=563,942)$, parity $2(\mathrm{n}=415,867)$, parity $3(\mathrm{n}=251,010)$, and parity 4 and above $(\mathrm{n}=209,721)$. Preliminary analysis indicated that means for parities 4 and above were not significantly different $(P<0.05)$, and the number of calving records per parity rapidly diminished with parity 3 and greater (Figure 1). Calving dates were categorized as being in 1 of 4 seasons based on month: season 1 = December through February, season $2=$ March through May, season $3=$ June

Table 1. Breakdown of records, herds, animals, and sires per breed with corresponding average twinning rates

\begin{tabular}{lccccc}
\hline Breed & Herds (no.) & Animals (no.) & Sires (no.) & Total records (no.) & Average twinning (\%) \\
\hline Holstein $^{1}$ & 3,074 & 831,579 & 20,317 & $1,806,505$ & - \\
Holstein $^{2}$ & 1,748 & 658,436 & 2,223 & $1,440,540$ & 29,378 \\
Jersey $^{2}$ & 491 & 14,938 & 1,767 & 11,725 & 2.7 \\
Brown Swiss $^{2}$ & 318 & 5,466 & 724 & 6,062 & 4.6 \\
Guernsey $^{2}$ & 80 & 2,846 & 357 & 2,151 & 3.2 \\
Ayrshire $^{2}$ & 95 & 983 & 258 & 1,359 & 5.0 \\
Milking Shorthorn $^{2}$ & 63 & 563 & 193 & .7 \\
\hline
\end{tabular}

${ }^{1}$ Number of records after removal of herds and sires with fewer than 100 records. Data used in the heritability analysis. All other breeds had fewer than 20 sires after similar editing and were not used in heritability estimation.

${ }^{2}$ Number of records before removal of herds and sires with fewer than 100 records. 


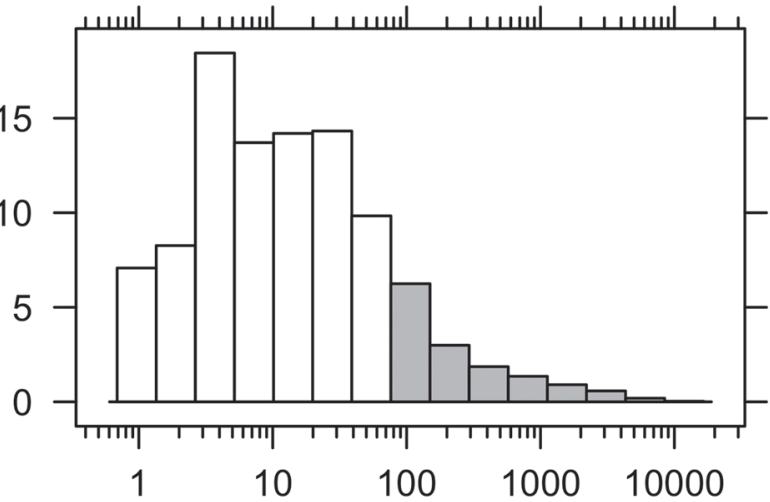

Daughers per Sire

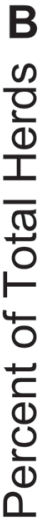

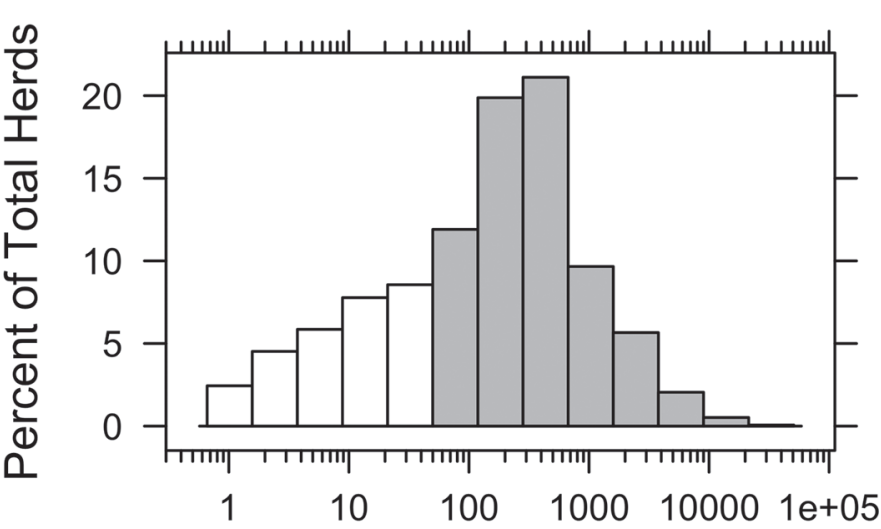

Records per Herd

C

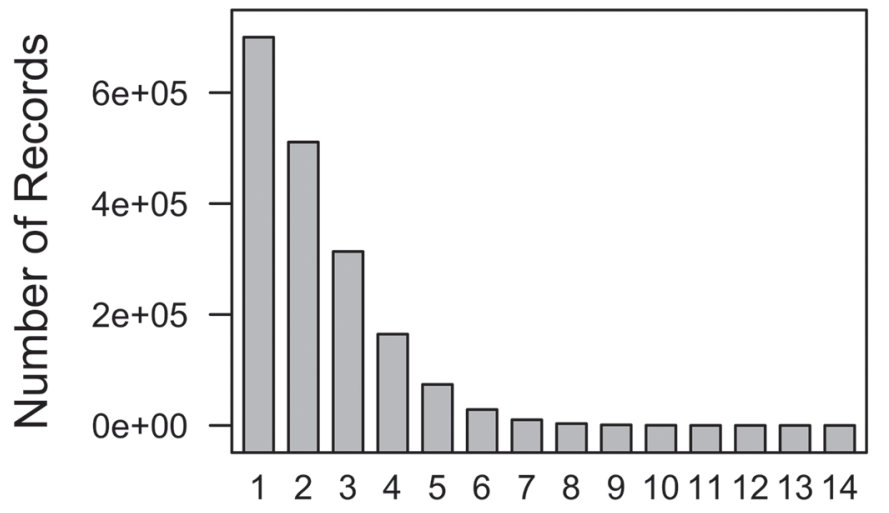

Parity

Figure 1. (A) Distribution of daughters per sire plotted on a $\log _{10}$ scale. Bars in gray represent sires that were kept after removing sires with fewer than 100 daughter records. (B) Distribution of records per herd plotted on a log scale. Bars in gray represent herds that were kept after removing those with fewer than 100 records. (C) Distribution of the number of calving records by parity for the data set before exclusion for low daughters per sire $(<100)$ or low records per herd $(<100$; $\mathrm{n}=1,806,505)$. through August, and season $4=$ September through November. In these data, year is the $7 \mathrm{yr}$ from 2010 to 2016 in which a calving was recorded.

Estimates of genetic effects for sires on twinning rate were regressed on year of birth for each sire to evaluate genetic trend for twinning rate. Heritability was estimated using variance components for sire, animal permanent environmental, and residual effects as

$$
h^{2}=\frac{\sigma_{s}^{2} \times 4}{\sigma_{s}^{2}+\sigma_{p}^{2}+\sigma_{e}^{2}} \text {. }
$$

For TLM, the underlying scale for the residual variance was $\frac{\pi^{2}}{3} \sim 3.3$ (Gilmour et al., 2015) for the logit link and was used as a coefficient to return residual variance to approximately 1 for heritability analysis. Additionally, the variance components for the TLM were $\sigma_{s_{T}}^{2}$, $\sigma_{p_{T}}^{2}$, and $\frac{\pi^{2}}{3}$, respectively. Both LM and TLM models were executed as restricted maximum likelihood models (Gilmour et al., 2015). Repeatability was estimated using the variance components for sire, animal permanent environmental, and residual effects as

$$
r=\frac{\left(\sigma_{s}^{2} \times 4\right)+\sigma_{p}^{2}}{\sigma_{s}^{2}+\sigma_{p}^{2}+\sigma_{e}^{2}} .
$$

Similarly, for heritability estimation from the TLM model, the corresponding variance components were $\sigma_{s_{T}}^{2}, \sigma_{p_{T}}^{2}$, and $\frac{\pi^{2}}{3}$, respectively.

Our results showed strong evidence $(P<0.001)$ for fixed effects of herd, year, season, and parity on twinning rate. Twinning rate increased with parity (Table 2 ), with the largest change in effect between parity $1(0.3 \%)$ and parity $2(4.3 \%)$. Previous studies with Holstein cattle have shown increases in twinning with parity, with twinning rates between 0.6 and $1.63 \%$ in parity 1 and ranging between 3.01 and $6.48 \%$ in later parities (Cady and Van Vleck, 1978; Karlsen et al., 2000; Johanson et al., 2001; Ghavi Hossein-Zadeh et al., 2009). Additionally, Karlsen et al. (2000) and Johanson et al. (2001) each reported the largest change between parity 1 and parity 2 , with increases from 0.7 to $2.8 \%$ and 1.63 to $5.22 \%$, respectively.

June through August (season 3) had the highest twinning rate among seasons (Table 2), which coincides with a conception period of September through November. Rutledge (1975), reviewing previous reports on twinning, stated that 2 periods of conception were 
Table 2. Least squares means and SE for parity, season, and year fixed effects

\begin{tabular}{lcl}
\hline Effect $^{1}$ & LSM estimate & SE \\
\hline Parity & 0.0030 & \\
1 & 0.0425 & 0.0004 \\
2 & 0.0690 & 0.0004 \\
3 & 0.0763 & 0.0005 \\
$4+$ & & 0.0005 \\
Season & 0.0459 & \\
1 & 0.0467 & 0.0004 \\
2 & 0.0519 & 0.0005 \\
3 & 0.0462 & 0.0004 \\
4 & & 0.0004 \\
Year & 0.0441 & 0.0008 \\
2010 & 0.0438 & 0.0006 \\
2011 & 0.0470 & 0.0005 \\
2012 & 0.0501 & 0.0005 \\
2013 & 0.0505 & 0.0005 \\
2014 & 0.0486 & 0.0005 \\
2015 & 0.0497 & 0.0005 \\
2016 & & \\
\hline
\end{tabular}

${ }^{1}$ Effects of season, parity, and year were significant $(P<0.0001)$. Season 1 = December to February; season $2=$ March to May; season $3=$ June to August; season $4=$ September to November.

associated with increased twinning rate, one of which (September to October) coincides with our findings. Cady and Van Vleck (1978) found peak of twins in calving between May and July (conceived between September and November), overlapping with the highest twinning rate season observed in the current analysis. Herd effects can vary due to a contribution of multiple management factors such as nutrition, culling practices, and reproductive protocols (Rutledge, 1975; Kinsel et al., 1998).

Previous average twinning rates ranged from 4.82 to $5.02 \%$ in the US Holstein breed (Cady and Van Vleck, 1978; Johanson et al., 2001). Average twinning rate in the current data was $4.8 \%$, comparable with these previous reports. A genetic trend for increasing twinning was evidenced by a significant regression of sire genetic effects on birth year $(P<0.001)$, with a regression coefficient of $0.0003 \pm 0.0001$.

Estimates of heritability were $0.0192 \pm 0.0009$ and $0.1420 \pm 0.0069$ for the LM and TLM, respectively. This indicates a lowly heritable trait, which concurs with previous findings. The higher heritability estimate from TLM versus LM was expected due to the different underlying distributions for the models. Heritability estimates for LM are in good agreement with previous reports of linear model heritability estimates, which ranged from 1.7 to $9.0 \%$, whereas the TLM is slightly higher compared with previous threshold model estimates, ranging from 8.0 to 10.5\% (Syrstad, 1974; Cady and Van Vleck, 1978; Gregory et al., 1990; Ron et al., 1990; Van Vleck et al., 1991; Johanson et al., 2001).
Repeatabilities of twinning rate from the LM and TLM were $0.0443 \pm 0.0012$ and $0.2310 \pm 0.0072$, respectively. Our result on the LM scale is within the range of previous findings (0-6.3\%; Bowman and Hendy, 1970; Syrstad, 1974). Few published estimates of repeatability from threshold model analyses are available in the scientific literature. Moioli et al. (2017) reported a repeatability estimate of $0.286 \pm 0.012$ from a threshold model analysis of twinning rate in Maremmana cattle, and Wolc et al. (2006) reported a repeatability estimate ranging from 0.33 to 0.34 in threshold model analyses of twinning rate in Thoroughbred horses.

The results reported here indicate that twinning rate is a lowly heritable and lowly repeatable trait that is affected by herd, year, season, and parity. This data set is one of the largest used thus far in estimation of heritability and repeatability of twinning rate and provides current estimates of each as well as fixed effects of season, parity, and year. The nonzero estimate of heritability and repeatability for twinning rate suggests the opportunity to improve this trait (i.e., reduce twinning rate) by selection.

\section{ACKNOWLEDGMENTS}

This project was supported by USDA Hatch Act Formula Funds (WIS019372) Doubling Down: Further Analysis of a Major Gene for Bovine Ovulation Rate and Development of a System to Exploit It. We thank AgSource Cooperative Services (Verona, WI) for providing the phenotypic records used in this study and the National Association of Animal Breeders (Madison, WI) for pedigree data.

\section{REFERENCES}

Andreu-Vázquez, C., I. Garcia-Ispierto, S. Ganau, P. M. Fricke, and F. López-Gatius. 2012. Effects of twinning on the subsequent reproductive performance and productive lifespan of high-producing dairy cows. Theriogenology 78:2061-2070. https://doi.org/10 .1016/j.theriogenology.2012.07.027.

Beerepoot, G. M. M., A. A. Dykhuizen, Y. Nielen, and Y. H. Schukken. 1992. The economics of naturally occurring twinning in dairy cattle. J. Dairy Sci. 75:1044-1051. https://doi.org/10.3168/jds .S0022-0302(92)77848-5.

Bowman, J. C., and C. R. C. Hendy. 1970. The incidence, repeatability and effect on dam performance of twinning in British Friesian cattle. Anim. Prod. 12:55-62. https://doi.org/10.1017/ S0003356100028725.

Cady, R. A., and L. D. Van Vleck. 1978. Factors affecting twinning and effects of twinning in Holstein dairy cattle. J. Anim. Sci. 46:950-956. https://doi.org/10.2134/jas1978.464950x.

Chapin, C. A., and L. D. Van Vleck. 1980. Effects of twinning on lactation and days open in Holsteins. J. Dairy Sci. 63:1881-1886. https://doi.org/10.3168/jds.S0022-0302(80)83155-9.

Fricke, P. M. 2001. Twinning in dairy cattle. Prof. Anim. Sci. 17:6167. https://doi.org/10.15232/S1080-7446(15)31599-0.

Ghavi Hossein-Zadeh, N., A. Nejati-Javaremi, S. R. Miraei-Ashtiani, and H. Kohram. 2009. Estimation of variance components and 
genetic trends for twinning rate in Holstein dairy cattle of Iran. J. Dairy Sci. 92:3411-3421. https://doi.org/10.3168/jds.2008-1631.

Gilmour, A. R., B. J. Gogel, B. R. Cullis, S. J. Welham, and R. Thompson. 2015. ASReml User Guide. VSN Int., Hemel Hempstead, UK.

Gregory, K. E., S. E. Echternkamp, G. E. Dickerson, L. V. Cundiff, R. M. Koch, and L. D. Van Vleck. 1990. Twinning in cattle: I. Foundation animals and genetic and environmental effects on twinning rate. J. Anim. Sci. 68:1867-1876.

Hossein-Zadeh, N. G. 2010. The effect of twinning on milk yield, dystocia, calf birth weight and open days in Holstein dairy cows of Iran. J. Anim. Physiol. Anim. Nutr. (Berl.) 94:780-787. https:// doi.org/10.1111/j.1439-0396.2009.00963.x.

Johanson, J. M., P. J. Berger, B. W. Kirkpatrick, and M. R. Dentine. 2001. Twinning rates for North American Holstein sires. J. Dairy Sci. 84:2081-2088. https://doi.org/10.3168/jds.S0022 -0302(01)74653-X.

Karlsen, A., J. Ruane, G. Klemetsdal, and B. Heringstad. 2000. Twinning rate in Norwegian cattle: Frequency, (co)variance components, and genetic trends. J. Anim. Sci. 78:15-20.

Kay, R. M. 1978. Changes in milk production, fertility and calf mortality associated with retained placentae or the birth of twins. Vet. Rec. 102:477-479. https://doi.org/10.1136/vr.102.22.477.

Kinsel, M. L., W. E. Marsh, P. L. Ruegg, and W. G. Etherington. 1998. Risk factors for twinning in dairy cows. J. Dairy Sci. 81:989993. https://doi.org/10.3168/jds.S0022-0302(98)75659-0.

Komisarek, J., and Z. Dorynek. 2002. Genetic aspects of twinning in cattle. J. Appl. Genet. 43:55-68.

Moioli, B., R. Steri, C. Marchitelli, G. Catillo, and L. Buttazzoni. 2017. Genetic parameters and genome-wide associations of twin- ning rate in a local breed, the Maremmana cattle. Animal 11:16601666. https://doi.org/10.1017/S1751731117000283.

Nielen, M., Y. H. Schukken, D. T. Scholl, H. J. Wilbrink, and A. Brand. 1989. Twinning in dairy cattle: A study of risk factors and effects. Theriogenology 32:845-862. https://doi.org/10.1016/0093 -691X(89)90473-1.

Ron, M., E. Ezra, and J. Weller. 1990. Genetic analysis of twinning rate in Israeli Holstein cattle. Genet. Sel. Evol. 22:349-359. https://doi.org/10.1186/1297-9686-22-3-349.

Rutledge, J. J. 1975. Twinning in cattle. J. Anim. Sci. 40:803-815. https://doi.org/10.2527/jas1975.405803x

Sawa, A., M. Bogucki, and M. Glowska. 2015. Effect of single and multiple pregnancies on performance of primiparous and multiparous cows. Arch. Anim. Breed. 58:43-48. https://doi.org/10.5194/aab $-58-43-2015$.

Syrstad, O. 1974. Genetic aspects of twinning in dairy cattle. Acta Agric. Scand. 24:319-322. https://doi.org/10.1080/00015127409434208.

Van Vleck, L. D., K. E. Gregory, and S. E. Echternkamp. 1991. Ovulation rate and twinning rate in cattle: Heritabilities and genetic correlation. J. Anim. Sci. 69:3213-3219. https://doi.org/10.2527/ 1991.6983213x.

Wolc, A., A. Bresińska, and T. Szwaczkowski. 2006. Genetic and permanent environmental variability of twinning in Thoroughbred horses estimated via three threshold models. J. Anim. Breed. Genet. 123:186-190. https://doi.org/10.1111/j.1439-0388.2006.00575 .x.

Young, A. S., and B. W. Kirkpatrick. 2016. Frequency of leukochimerism in Holstein and Jersey twinsets. J. Anim. Sci. 94:4507-4515. https://doi.org/10.2527/jas.2016-0623. 